\title{
PERANCANGAN SISTEM INFORMASI CHECKING TARIF DAN TRACKING BARANG MENGGUNAKAN API DI PT. DAKOTA INDONESIA EXPRESS
}

\author{
${ }^{1}$ Supono, ${ }^{2}$ Awlita Pramayany, \\ 1,2,Program Studi D III Manajemen Informatika, Politeknik Pos Indonesia \\ E-mail: ${ }^{1}$ supono@poltekpos.ac.id, 2-awlitapramayany@gmail.com
}

\begin{abstract}
ABSTRAK
Saat ini banyak perusahaan telah menggunakan sistem terkomputerisasi dalam mengolah datanya. PT. Dakota Indonesia Express merupakan perusahaan Jasa Pengiriman Ekspres yang berkembang pesat dan tercatat sebagai anggota Asperindo sejak tahun 2003. Namun, untuk mengetahui tarif pengiriman (proses checking tarif) dan tracking barang belum terintegrasi dengan sistem informasi perusahaan secara online dan masih dilakukan dengan cara menelpon bagian operasional, kemudian bagian operasional mengecek ke aplikasi di komputer local, sehingga kepuasan pelanggan dalam mengetahui informasi mengenai tarif kirman dan status kiriman (tracking) belum dapat terpenuhi. Oleh sebab itu, diperlukan Sistem Informasi Checking Tarif dan Tracking Barang.

Dalam perancangan sistem informasi ini, diawali dengan menganalisis proses bisnis yang sedang berjalan menggunakan BPMN (Business Process Model and Notation). Kemudian dilanjutkan dengan merancang sebuah sistem informasi dengan menggunakan pemodelan UML (Unified Modeling Language).

Hasil akhir dari penelitian ini adalah berupa perancangan Sistem Informasi Checking Tarif dan Tracking Barang Menggunakan layanan API (Application Programming Interface) yang memiliki fitur check tarif kiriman (tarif normal dan tarif khusus) dan check status kiriman (tracking) barang.

Kata Kunci: Perancangan Sistem Informasi, Check Tarif dan Tracking, BPMN, UML
\end{abstract}

ABSTRACT
Today many companies have used computerized systems to process their data. PT. Dakota Indonesia Express is a fast growing Express Delivery Service company and registered as a member of ASPERINDO since 2003. However, to find out the shipping price (the process of checking rates) and tracking of goods has not been integrated with the company's information system online and is still doing by calling the operational section, then the operational section checks the application on the local computer, so customer satisfaction in knowing information about the shipping rates and shipment status (tracking) has not been fulfilled. Therefore, it is necessary to check and tracking the goods.

In design this information system, it begins by analyzing the ongoing business processes using BPMN (Business Process Model and Notation). Then proceed with designing an information system using UML (Unified Modeling Language) modeling.

The final result of this research is in the form of designing a Checking Information System for Goods Rates and Tracking Using API (Application Programming Interface) services that have features for checking freight rates (normal and special rates) and checking the status of the shipment (tracking) of goods.

Keywords: Design of Information Systems, Check Rates and Tracking, BPMN, UML

\section{PENDAhULUAN}

Perkembangan teknologi dan informasi saat ini semakin hari semakin berkembang ke berbagai sektor, khususnya dalam sebuah bisnis yang semakin hari semakin ketat. Sebuah perusahaan dituntut agar dapat memberikan pelayanan yang baik kepada pelanggan, karena pelanggan merupakan aset yang sangat penting dalam sebuah perusahaan, sehingga perusahaan harus melakukan strategi yang tepat agar dapat bersaing dalam dunia bisnis. Salah satu cara yang dapat dilakukan perusahaan agar mampu bersaing dalam dunia bisnis adalah dengan menerapkan sebuah sistem Customer Relationship Management (CRM). CRM merupakan salah satu sarana dalam menjaga hubungan baik antara perusahaan dengan pelanggan yang berfokus pada jangka panjang dan hubungan yang berkelanjutan [4]. Melalui CRM perusahaan dapat memberikan kepuasan kepada pelanggan. Salah satu contoh penerapan dari CRM 
tersebut adalah dengan adanya fasilitas checking tarif kiriman dan status kiriman (tracking) barang di sebuah perusahaan jasa pengiriman [1].

PT. Dakota Indonesia Express merupakan perusahaan Jasa Pengiriman Ekspres Indonesia yang cukup berkembang pesat telah tercatat sebagai anggota Asperindo (Asosiasi Perusahaan Jasa Pengiriman Ekspres Indonesia) semenjak tahun 2003. Namun, proses checking tarif dan tracking barang masih dilakukan dengan cara menelpon bagian operasional sehingga kepuasan pelanggan dalam mengetahui informasi mengenai tarif kirman dan tracking barang belum dapat terpenuhi. Untuk memenuhi kebutuhan tersebut, perusahaan dapat menerapkan sistem informasi checking tarif dan tracking barang terintegrasi berbasis web [2]. Perancangan sistem informasi ini menggunakan API (Application Programming Interface) agar dapat terintegrasi dengan sistem informasi perusahaan. Sistem infromasi checking tarif dan tracking berbasis web ini menyediakan pencarian tarif kiriman dan status kiriman (tracking) barang di PT. Dakota Indonesia Express. Oleh karena itu, penelitian ini diberi judul "Perancangan Sistem Informasi Checking Tarif dan Tracking Barang Menggunakan API di PT. Dakota Indonesia Express".

Berdasarkan latar belakang yang ada, maka dapat dirumuskan masalah: Untuk mengethau mengetahui informasi mengenai tarif kiriman secara online belum dapat terpenuhi, karena proses check tarif dan tracking status kiriman masih dilakukan dengan menelpon bagian operasional, kemudian bagian operasional akan mengecek ke aplikasi komputer lokal. Sistem belum terintegrasi antara sistem informasi yang ada di komputer local dengan sistem informasi yang sudah online. Berdasarkan rumusan masalah yang telah dipaparkan, maka adapun tujuan penelitian ini adalah merancang Sistem Informasi Checking Tarif dan Tracking Barang Menggunakan Layanan API di PT. Dakota Indonesia Express secara online dan terintegrasi dengan sistem yang ada di perusahaan PT. Dakota Indonesia.

Adapun penelitian ini, permasalahan dibatasi menjadi beberapa hal, sebagai berikut: merancang Sistem Informasi yang memiliki fitur validasi login, kelola user, kelola pelanggan, check status kiriman (tracking) berbasis web, check tarif normal berbasis web, check tarif khusus berbasis web, Sistem informasi ini dirancang menggunakan API dari sistem informasi operasional yang ada di PT. Dakota Indonesia Express.

\section{METODE DAN PERANCANGAN SISTEM}

Penelitian ini dilakukan dengan beberapa tahapan yaitu: analisis sistem yang meliputi aktivitas analisis aktivitas utama dan pendukung, analisis bisnis user, dan analisis proses bisnis yang sedang berjalan. Tahap berikutnya adalah melakuakn perancangan dengan melakukan perancangan sistem dan perancangan antar muka, dan tahap terakhir melakukan penulisan laporan hasil penelitian.

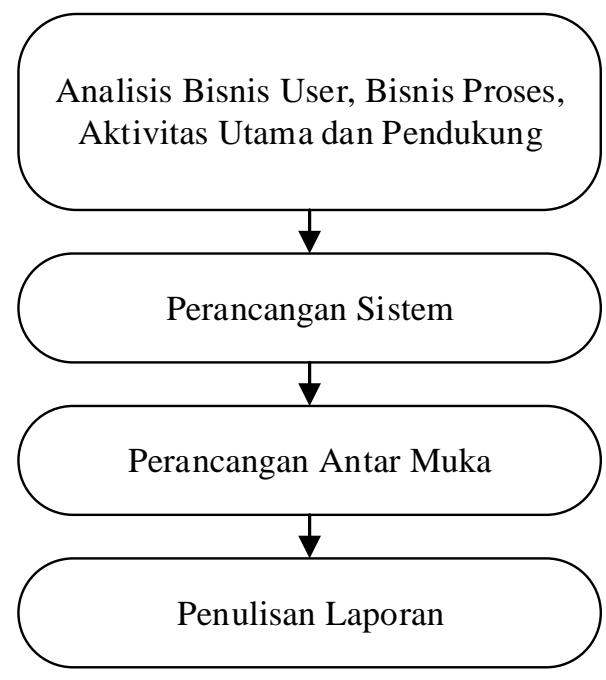

Gambar 1. Tahapan Penelitian 


\subsection{Analisis Sistem yang Sedang Berjalan}

Analisis umum dilakukan dengan menggambarkan rantai nilai beserta penjelasannya. Rantai nilai porter adalah model yang digunakan untuk membantu menganalisis aktivitas-aktivitas spesifik yang dapat menciptakan nilai dan keuntungan kompetitif bagi organisasi.

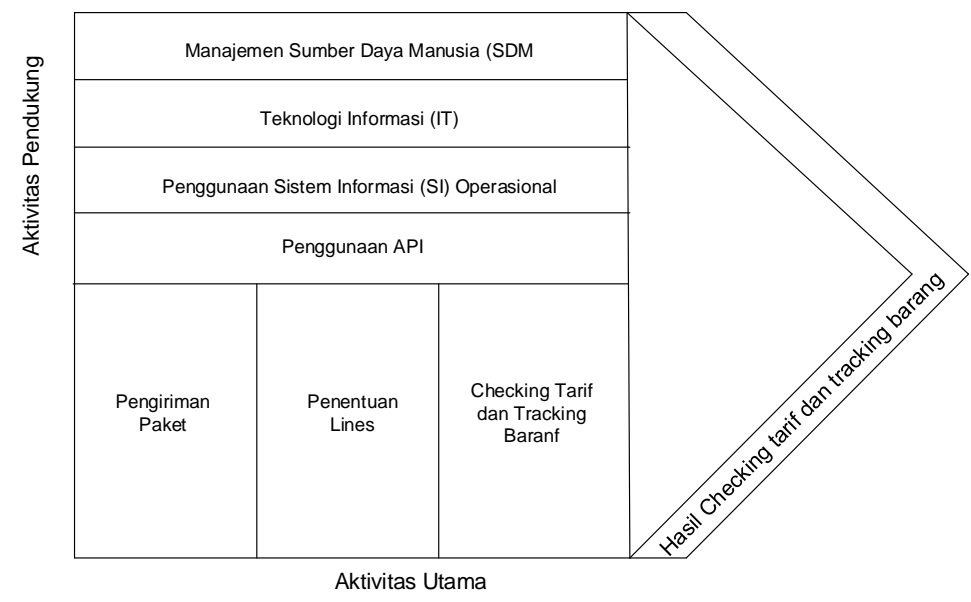

Gambar 2. Rantai Nilai Porter

Adapun aktivitas utama yang dilakukan di PT. Dakota Indonesia Express adalah pengiriman barang / paket, penentuan line, checking tarif dan tracking barang. Apabila ingin mengirim barang, pelanggan dapat melakukan checking tarif dan setelah barang dikirim, pelanggan dapat mengetahui status kiriman dengan melakukan checking tracking barang. Aktivitas pendukung yang ada di PT. Dakota Indonesia Express adalah manajemen Sumber Daya Manusia (SDM), Teknologi dan Informasi (IT), penggunaan SI Operasional, dan penggunaan API. Margin yang dihasilkan dari aktivitas utama yang dilakukan adalah hasil checking tarif dan tracking barang. Aktivitas yang menjadi objek analisis adalah aktivitas yang ada di bagiam kepuasan pelanggan (customer satisfaction), yaitu checking tarif dan tracking barang.

Business user yang terdapat dalam Perancangan Sistem Informasi Checking Tarif dan Tracking Barang Menggunakan API di PT. Dakota Indonesia Express adalah sebagai berikut : Pelanggan Umum, merupakan pihak yang dapat melakukan check tarif dan status kiriman (tracking). Pelanggan Khusus, merupakan pihak yang dapat melakukan check tarif khusus dan status kiriman (tracking). Bagian Operasional, merupakan pihak yang dapat memberitahu tarif normal kepada Pelanggan Umum dan tarif khusus kepada Pelanggan Khusus, serta dapat memberitahu Pelanggan Umum dan Pelanggan Khusus tentang status kiriman (tracking) dengan melakukan check status surat jalan di sistem informasi operasional. Bagian Keuangan, merupakan pihak yang mengeluarkan list tarif normal dan list tarif khusus, serta dapat memberitahu tentang tarif khusus kepada Bagian Operasional jika ada Pelanggan Umum yang menanyakan tarif khusus.

Business Process dimodelkan dengan menggunakan BPMN [3]. Adapun Business Process yang terdapat di PT. Dakota Indonesia Express (as is atau yang sedang berjalan) adalah sebagai berikut: 


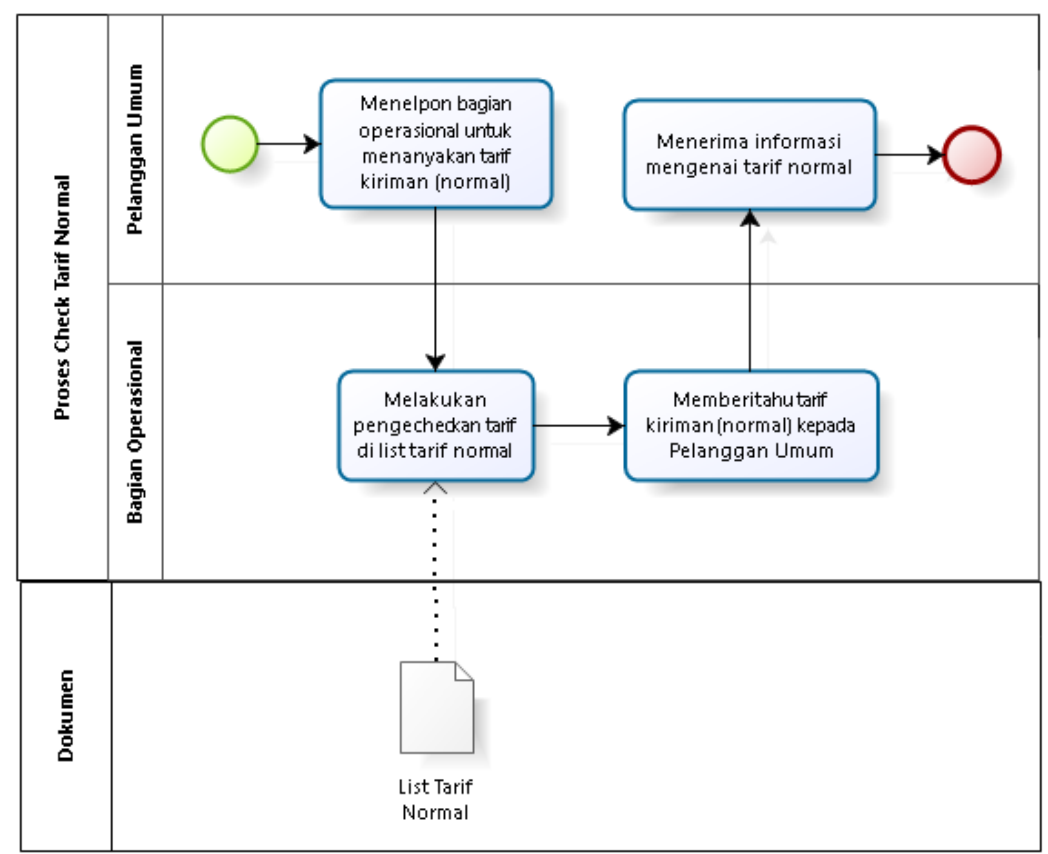

Gambar 3 BPMN Proses Check Tarif Normal

Penjelesan dari prosedur check tarif normal adalah sebagai berikut :

1. Pelanggan Umum menelpon bagian operasional untuk menanyakan tarif kiriman (normal).

2. Bagian Operasional melakukan pengecheckan tarif di list tarif normal.

3. Bagian Operasional memberitahu tarif kiriman (normal) kepada Pelanggan Umum.

4. Pelanggan Umum menerima informasi mengenai tarif norma

\subsection{Perancangan Sistem}

Proses checking tarif dan trackin barang pada PT. Dakota Indonesia Express saat ini masih dilakukan dengan menelpon bagian operasional, sehingga kepuasan pelanggan dalam mengetahui informasi mengenai tarif kirman dan status kiriman (tracking) belum dapat terpenuhi. Untuk memenuhi kebutuhan tersebut, perusahaan dapat menerapkan sistem informasi checking tarif dan status kiriman (tracking) barang secara online terintegrasi berbasis web yang menyedikan fitur pencarian tarif (normal dan khusus) dan status kiriman (tracking) barang. Berbagai proses yang dianalisis pada Sistem Informasi Checking Tarif dan Tracking Barang Menggunakan API di PT. Dakota Indonesia Express yaitu : Proses Validasi Login, Proses Kelola User, Proses Kelola Pelanggan, Proses Check Tarif Khusus, Proses Check Tracking Baranf, Proses Check Tarif Normal.

\section{- Use Case Diagram}

Pembangunan sistem didasarkan pada analisis yang telah dilakukan dengan tujuan menciptakan suatu Sistem Informasi Checking Tarif dan Tracking Barang Menggunakan API di PT.Dakota Indonesia Express. Sistem infromasi ini dibangun dengan pemodelan berorientasi objek dengan menggunakan Unified Modeling Language (UML) sebagai bahasa pemodelannya. use case merepresentasikan sebuah interaksi antara aktor dengan sistem serta hak-hak aktor dalam mengelola sistem. Pada gambar 3 merupakan perancangan use case diagram dari Sistem Informasi Checking Tarif dan Tracking Barang Menggunakan API di PT.Dakota Indonesia Express. 


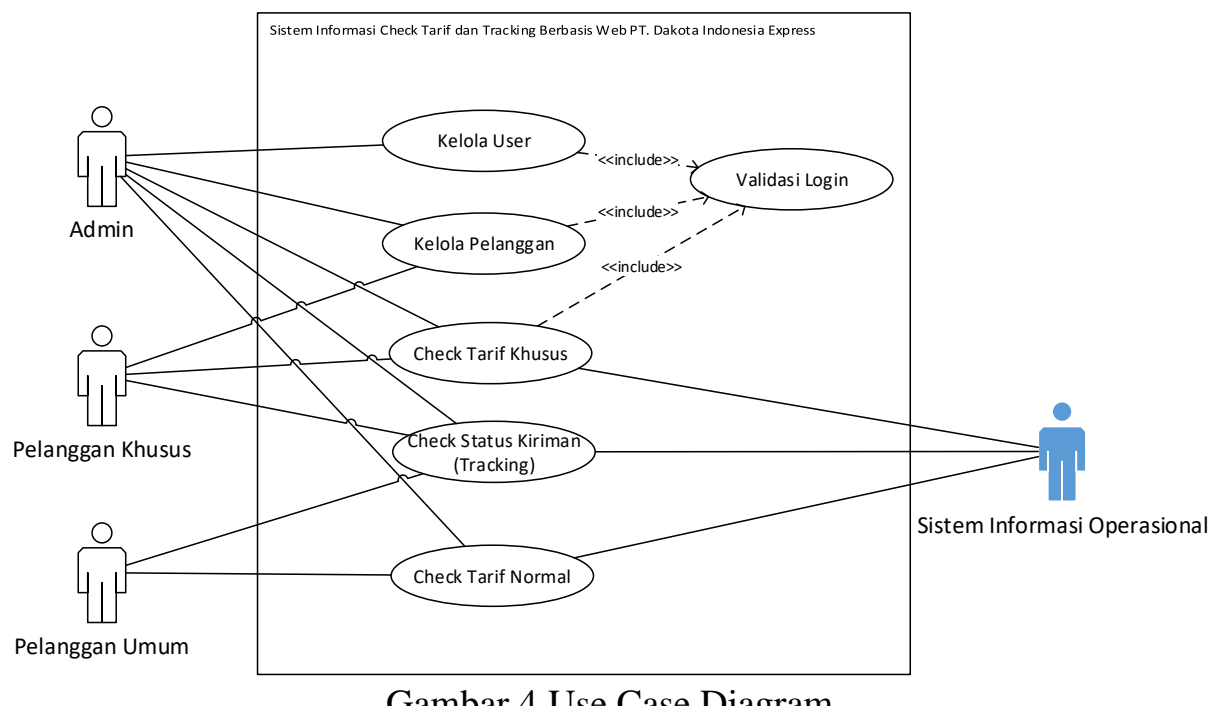

Gambar 4 Use Case Diagram

Berdasarkan gambar 3 Use Case diagram Sistem Informasi Checking Tarif dan Tracking Barang Menggunakan API di PT. Dakota Indonesia Express memiliki 3 aktor yaitu Admin, Pelanggan Khusus, dan Pelanggan Umum, serta SI Operasional perusahaan. Dan memiliki 6 use case yaitu validasi login, kelola user, kelola pelanggan, check tarif khusus, check tracking, dan check tarif normal

\section{- Class Diagram}

Class diagram adalah pemodelan yang menggambarkan keterkaitan atau hubungan antar kelas yang berisi atribut dan operasinya. Berikut class diagram dari sistem yang dibangun:

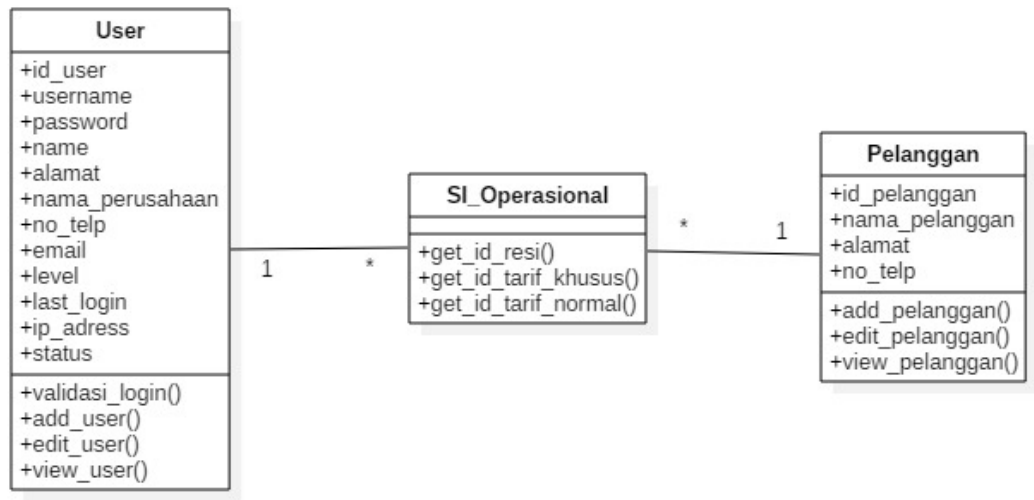

Gambar 5 Class Diagram

Berdasarkan Gambar 4 Class Diagram Sistem Informasi Checking Tarif dan Tracking Barang Menggunakan API di PT. Dakota Indonesia Express memilik 3 class yang saling terhubung satu dan lainnya. Untuk get data dari SI_Operasional, dihubungkan menggunakan API.

\section{- Perancangan Menu}

Perancangan menu meggambarkan menu-menu yang ada pada Sistem Informasi Checking Tarif dan Tracking Barang Menggunakan API di PT. Dakota Indonesia Express. Perancangan menu ini terdiri dari menu halaman Admin untuk mengelola user dan pelanggan. Halaman Pelanggan Khusus untuk mengelola pelanggan, check tarif khusus, dan check status kiriman (tracking). Halaman Pelanggan Umum untuk check tarif normal dan check status kiriman (tracking). 


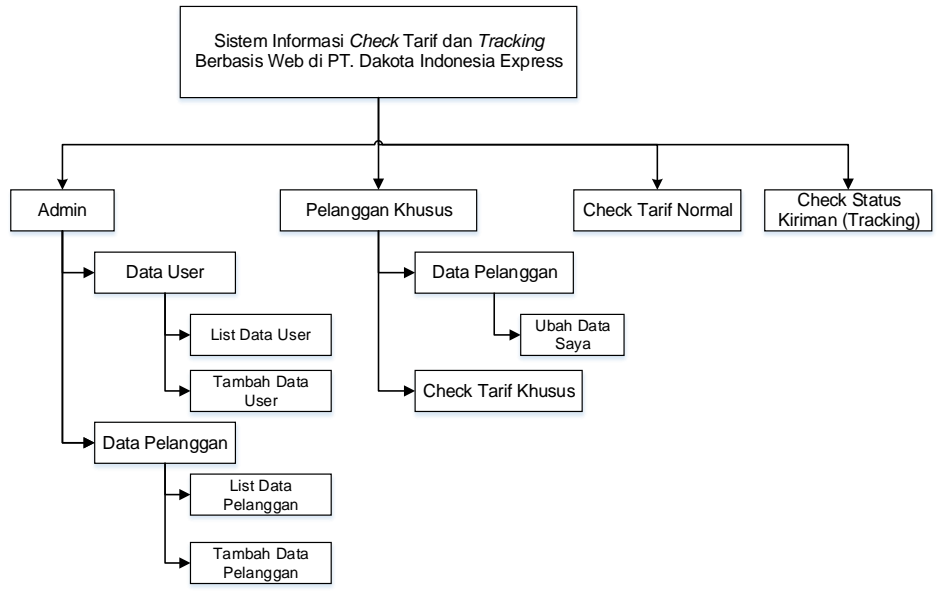

Gambar 6. Perancangan Menu

\section{- Perancangan Antar Muka}

Perancangan antarmuka menggambarkan tampilan dari aplikasi yang akan dimplementasi berdasarkan untuk Sistem Informasi Checking Tarif dan Tracking Barang Menggunakan API di PT. Dakota Indonesia Express. Berikut merupakan perancangan antarmuka halaman utama.

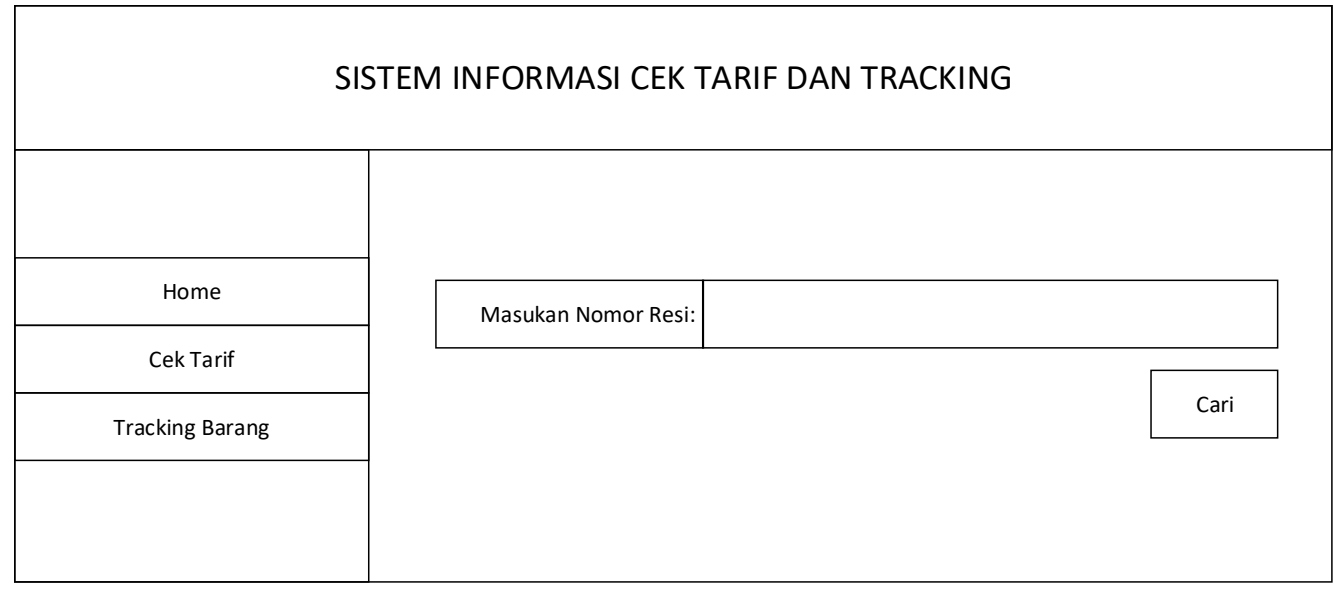

Gambar 7. Perancangan Antarmuka Halaman Utama

\section{HASIL DAN PEMBAHASAN}

Perancangan Sistem Informasi Checking Tarif dan Tracking Barang Menggunakan API di PT. Dakota Indonesia Express menggunakan pendekatan perancangan berbasis objek yaitu dengan menggunakan UML dalam hal ini digambarkan dalam Use Case Diagram. Secara umum perancangan sistem ini dimulai dari: (1) pelanggan melakukan pengiriman paket, (2) setelah itu pelanggan dapat mengecek status barang melalui website yang disediakan dan dapat melihat posisi dan status pengiriman apakah sudah sampai atau belum, jika belum ada di posisi mana. Berikut ini hasil prototype aplikasi untuk perancangan

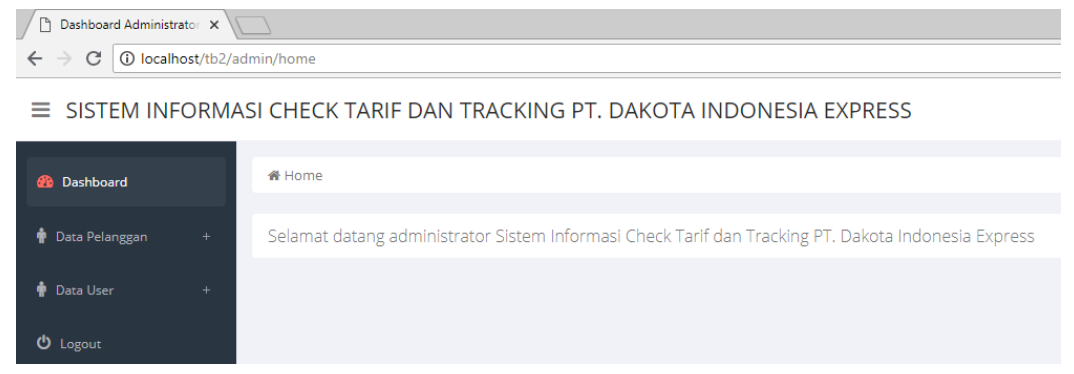

Gambar 8. Tampilan Prototipe Aplikasi Tracking 


\section{KESIMPULAN}

Setelah melakukan analisis dan perancangan Sistem Informasi Checking Tarif dan Tracking Barang Menggunakan API di PT. Dakota Indonesia Express, diperoleh beberapa kesimpulan yaitu :

1. Telah dihasilkan rancangan sistem informasi yang menyediakan fitur check tarif normal dan khusus, sehingga kepuasan pelanggan (customer satisfaction) dalam mengetahui informasi mengenai tarif kiriman dapat terpenuhi.

2. Telah dihasilkan rancangan sistem informasi yang menyediakan fitur check status kiriman (tracking) barang dan terintegrasi dengan sistem informasi perusahaan, sehingga kepuasan pelanggan (customer satisfaction) dalam mengetahui informasi mengenai status kiriman (tracking) barang dapat terpenuhi.

\section{REFERENSI}

[1] Dhika, H., Lukman, L., \& Fitriansyah, A. (2016). Perancangan sistem informasi jasa pengiriman barang berbasis web. Simetris: Jurnal Teknik Mesin, Elektro dan Ilmu Komputer, 7(1), 51-58.

[2] Supono, V. P. (2016). Pemrograman Web dengan Menggunakan PHP dan Framework Codeigniter. Yogyakarta: Deepublish.

[3] Dewi, L. P., Indahyanti, U., \& Hari, Y. (2012). Pemodelan Proses Bisnis Menggunakan Activity Diagram UML dan BPMN (Studi Kasus Frs Online). In Seminar Nasional Teknik Industri Waluyo Jatmiko V. Surabaya.

[4] Goodhue, D. L., Wixom, B. H., \& Watson, H. J. (2002). Realizing business benefits through CRM: hitting the right target in the right way. MIS Quarterly executive, 1(2), 79-94.

[5] Pengertian Tracking, https://www.andre.web.id/istilah-pada-tracking-resi-jne/ (diakses tanggal 15 juni 2018)

[7] Dennis Alan, dkk.2005. System Analysis And Design With UML Version 2.0.USA:WILEY

[8] Mengenal API

https://www.codepolitan.com/mengenal-apa-ituweb-api-5a0c2855799c8 (diakses tanggal 2 juli 2018) 